Development Center

Engineer Site Identification for the Tactical Environment

\title{
Methods of Analysis to Remotely Determine Material Degradation
}

Eric L. Kreiger, Joseph A. Gamez, Patrick J. Guertin, and

September 2018

George W. Calfas

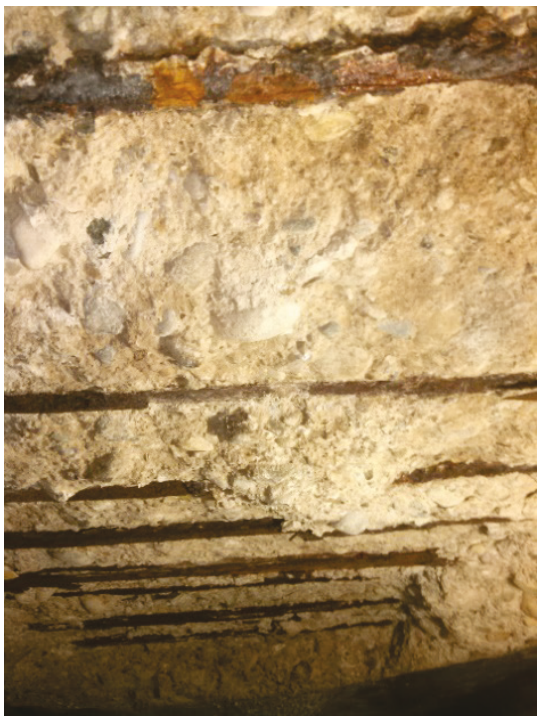

Left: Large temperature swings and high humidity led to spalling of concrete and exposing reinforcement that is undergoing corosion and loss of mass.

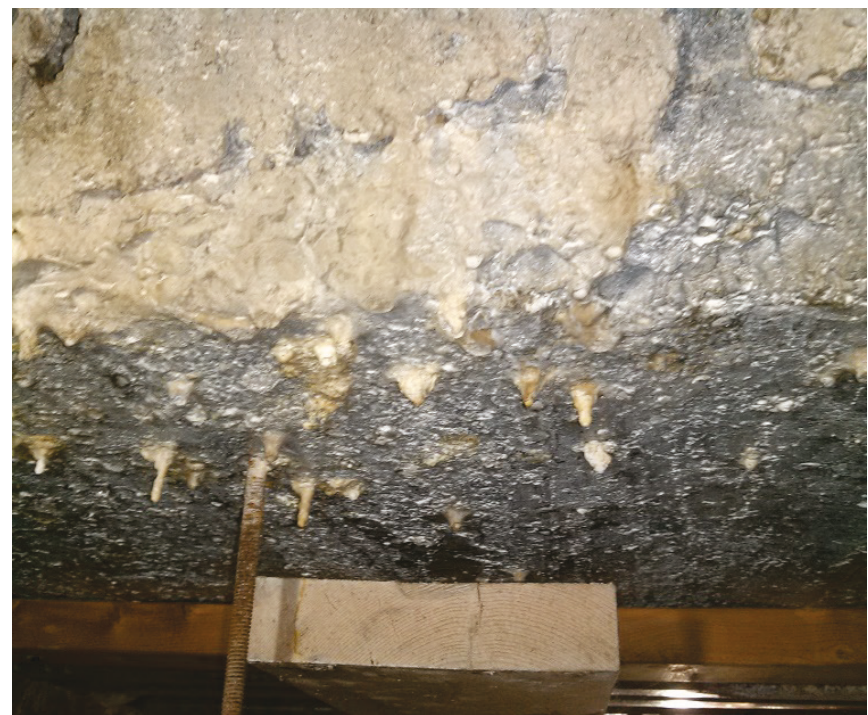


The U.S. Army Engineer Research and Development Center (ERDC) solves the nation's toughest engineering and environmental challenges. ERDC develops innovative solutions in civil and military engineering, geospatial sciences, water resources, and environmental sciences for the Army, the Department of Defense, civilian agencies, and our nation's public good. Find out more at www.erdc.usace.army.mil.

To search for other technical reports published by ERDC, visit the ERDC online library at http://acwc.sdp.sirsi.net/client/default. 


\section{Methods of Analysis to Determine Remote Material Degradation}

Eric L. Kreiger, Joesph A. Gamez, Patrick J. Guertin, and George W. Calfas

U.S. Army Engineer Research and Development Center (ERDC)

Construction Engineering Research Laboratory (CERL)

2902 Newmark Dr.

Champaign, IL 61826-9005

Final Report

Approved for public release; distribution is unlimited.

Prepared for Assistant Secretary of the Army for Acquisition, Logistics and Technology (ASA(ALT))

103 Army Pentagon

Washington, DC 20314-100

Under Project \#45509, “Military Facilities Engineering Technology” 


\section{Abstract}

The U.S. government and its military currently operate in a wide range of geographic locations. Due to the time, logistics, and costs of shipping or acquiring materials once in theater, it is advantageous for engineers and commanders to understand the relevant environmental conditions present that could cause untimely material degradation, especially for wood and concrete masonry units (CMUs). This publication provides an overview of research conducted to inform a remote selection of operational materials in a wide variety of climates. The information and analytical methods used will be incorporated in development of a remote assessment tool that can predict material degradation based on using global location data, as part of the Engineer Site Identification for the Tactical Environment (ENSITE) program. This document provides background and understanding of the (a) concept of climate zones and their effects on materials selection, (b) environmental factors that drive degradation, (c) mechanisms and other factors that cause degradation of wood and CMUs, and (d) how those mechanisms and factors relate to degradation.

DISCLAIMER: The contents of this report are not to be used for advertising, publication, or promotional purposes. Citation of trade names does not constitute an official endorsement or approval of the use of such commercial products. All product names and trademarks cited are the property of their respective owners. The findings of this report are not to be construed as an official Department of the Army position unless so designated by other authorized documents. 


\section{Contents}

Abstract.................................................................................................................................. if

Figures and Tables..............................................................................................................v

Preface .................................................................................................................. vi

Unit Conversion Factors........................................................................................vi

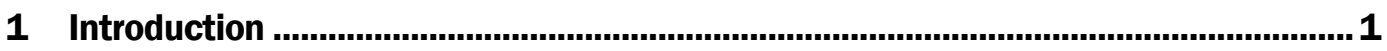

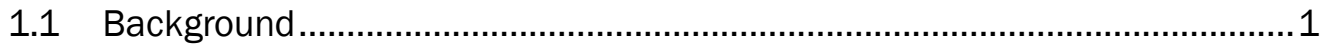

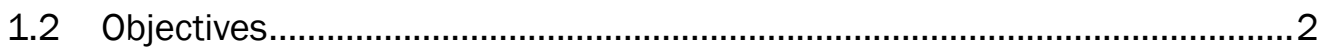

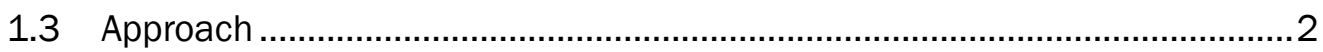

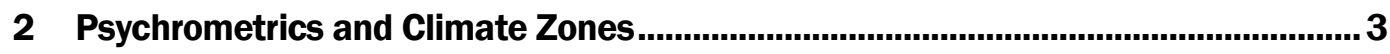

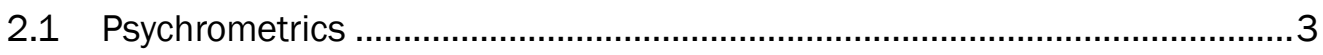

2.2 Climate zones ......................................................................................

2.2.1 Army Facilities Component System...................................................................... 4

2.2.2 American Society of Heating, Refrigeration, and Air Conditioning

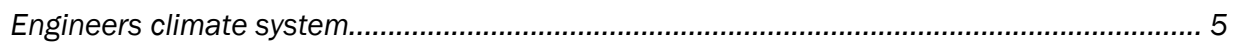

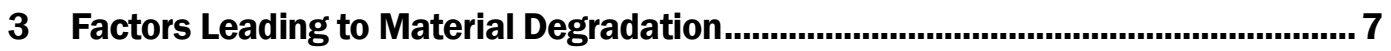

3.1 Mechanisms that cause degradation...................................................... 7

3.1.1 Temperature, heat, moisture........................................................................ 7

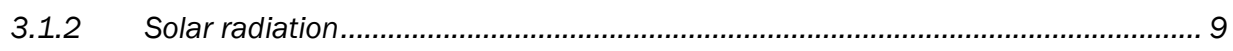

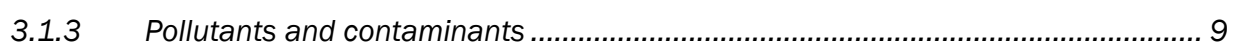

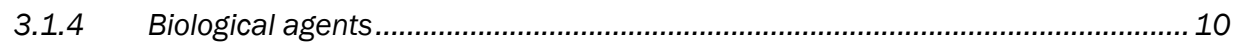

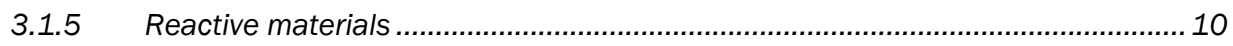

3.2 Chemical and physical properties of materials ..........................................10

3.3 Time of exposure ..............................................................................

4 Degradation of Wood.............................................................................................12

4.1 Mechanisms and other factors that cause degradation.......................... 12

4.1.1 Insects and marine borers........................................................................... 12

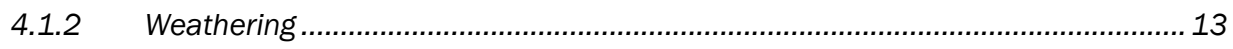

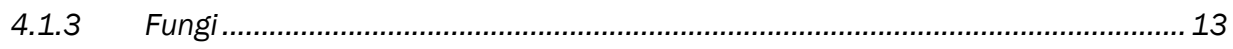

4.2 Environmental factors affecting wood degradation ................................ 13

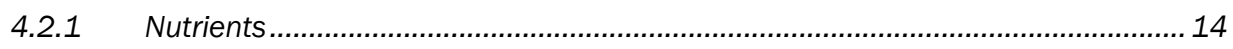

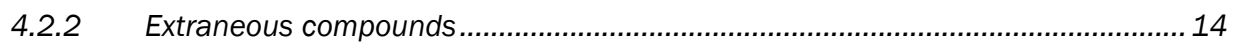

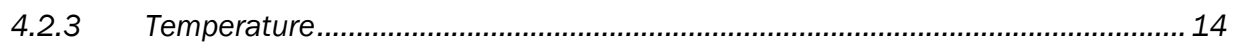

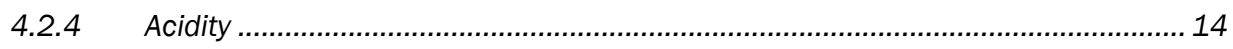

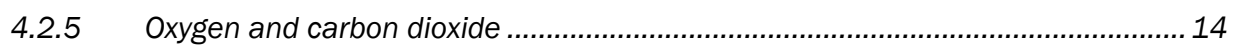

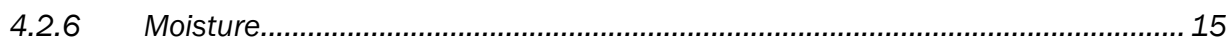

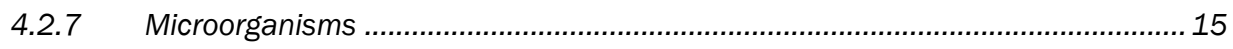

4.3 Predictive methods for degradation of wood ............................................. 
4.3.1 Development of a climate index by Scheffer (1971) .......................................... 16

4.3.2 Development of a decay rate estimation ............................................................. 21

4.3.3 An update to the Scheffer Index by Fernandez-Golfin et al. (2016) ...................... 23

4.3.4 An update to the Scheffer Index by Carll (2009).................................................. 24

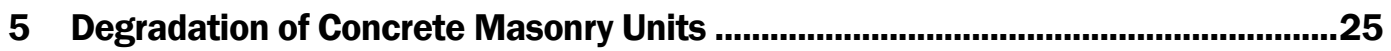

5.1 Mechanisms that cause degradation....................................................... 25

5.2 Predictive methods for the freeze-thaw degradation of CMUs .................... 26

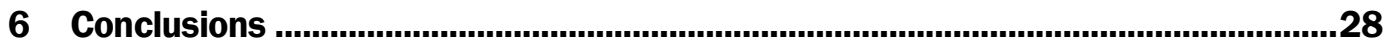

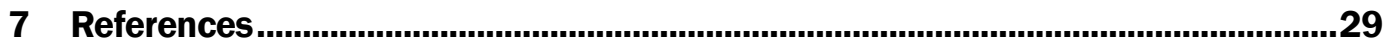

Report Documentation Page 


\section{Figures and Tables}

\section{Figures}

Figure 1. Climate zone map for the United States (Halverson et al 2014).......................... 6

Figure 2. Sample termite hazard map (Cookson and Trajstman 2002, 34)......................16

Figure 3. Growth rate of Lenzites trabea and Polyporus versicolor (from Scheffer 1971, 27).

Figure 4. Scheffer Index, map of the conterminous United States (from Scheffer 1971, 29).

Figure 5. Degradation hazard map for wooden structures above ground, using $k_{\text {climate }}$ (Wang, Leicester, and Nguyen 2008, 44).

Figure 6. Degradation hazard map for wooden structures above ground, using the Scheffer Index (Wang, Leicester, and Nguyen 2008, 44).

Figure 7. Weathering probability of concrete (IRC 2015).

\section{Tables}

Table 1. Summary of temperature, solar radiation, and relative humidity extremes within AFCS climate categories and zones (from TM 5-304) ............................... 4

Table 2. International climate zone definitions (ICC 2012). .............................................. 5

Table 3. Decay risk (from Fernandez-Golfin, et al. 2016, 597). 


\section{Preface}

This study was conducted for Assistant Secretary of the Army for Acquisition, Logistics and Technology (ASA(ALT)) under T45, "Military Facilities Engineering Technology," and Project Number 455009, "Contingency Base Site Identification Tool for the Tactical Environment." The technical monitor was Mr. Kurt Kinnevan, CEERD-CZT.

The work was performed under supervision of the Environmental Processes Branch (CNE) of the Installation Division (CN), U.S. Army Engineer Research and Development Center, Construction Engineering Research Laboratory (ERDC-CERL). At the time of publication, Mr. H. Garth Anderson was Chief, CEERD-CNE; Ms. Michelle Hanson was Chief, CEERD-CN; and Mr. Kurt Kinnevan, CEERD-CZT was the Technical Director for Infrastructure for Combat Operations. The Deputy Director of ERDC-CERL was Dr. Kirankumar Topudurti, and the Director was Dr. Lance D. Hansen.

COL Ivan P. Beckman was Commander of ERDC, and Dr. David W. Pittman was the Director. 


\section{Unit Conversion Factors}

\begin{tabular}{|l|l|l|}
\hline Multiply & By & To Obtain \\
\hline degrees Fahrenheit & $(\mathrm{F}-32) / 1.8$ & degrees Celsius \\
\hline square feet & 0.09290304 & square meters \\
\hline
\end{tabular}


[This page intentionally blank.] 


\section{Introduction}

\subsection{Background}

The decay of materials selected for military operations can have a dramatic effect on the mission's success and the health and wellbeing of personnel in contact with decayed materials. The use of materials that have been compromised by degradation can yield a mission-critical structure that is unusable. As the degradation of any component in a structure progresses, the structure's ability to support loads and resist unwanted movement decreases. It is feasible that materials could be delivered in a decayed state or decay once the structure is in service. Due to the logistics and the cost of shipping or acquiring materials in theater, it is advantageous for engineers and commanders to understand the relevant environmental conditions that could cause material degradation. This understanding will mitigate the related potential for operational or structural failures.

There is anecdotal evidence from recent in-theater operations that some building materials selected for use have underperformed, were difficult or expensive to obtain, have developed mold growths that led to sickness, or were rendered unserviceable through degradation from environmental factors. Taking into account the wide range of geographic locations in which the U.S. Government (USG) operates, there is a need for a rational method for selecting military operational materials that are suitable for both mission and environment. Given the right conditions, any material could degrade. However, wood and concrete masonry units (CMUs) are two materials that have shown evidence of decay during military operations, so those two materials were chosen for this study. (Other materials that could show signs of decay are steel, reinforced concrete, and plastics, but those materials are not discussed in this report.)

This report discusses the information and analytical methods required to develop a remote assessment tool that can predict material degradation using global location data. Development of such a tool for use in the Engineer Site Identification for the Tactical Environment (ENSITE) tool, which incorporates geographical information system (GIS) software, will be a powerful resource for successful decisions on the proper materials for military operations in a given environment. 


\subsection{Objectives}

This publication provides an overview of research conducted to inform of a tool to remotely select operational materials for military use in a wide variety of climates. Specifically, this document provides the reader with an understanding of the following:

- Concept of climate zones and how they can affect the proper selection of usable operational materials.

- Environmental factors that drive the degradation process of materials.

- Mechanisms and other factors that cause the degradation of wood and CMUs.

- How those mechanisms and factors relate to the rate of degradation.

\subsection{Approach}

Two operational materials were selected and reviewed in literature. This review determined whether there are existing correlations between the rate of a material's degradation and environmental factors. If no correlation existed, then the literature review focused on gathering the appropriate literature to guide the development of one. 


\section{Psychrometrics and Climate Zones}

\subsection{Psychrometrics}

Psychrometrics is the study of the thermodynamic properties of gas-vapor mixtures (Machine Applications Corporation 1999). Psychrometric properties of moist air are used to (a) define climate zones, (b) cause moisture and heat flow through materials, and (c) predict a material's susceptibility to decay (Straub and Burnett 2005). Psychrometric properties and their definitions are listed below:

- Dry bulb temperature (DBT) is the temperature indicated by a thermometer.

- Wet bulb temperature (WBT) is recorded by using a thermometer covered by a moist cloth over which air is passed. The DBT equals the WBT at $100 \%$ humidity.

- Dew point temperature is the temperature at which water vapor condenses into liquid.

- Humidity is the amount of water vapor in the air. Types of humidity measurements include specific humidity, absolute humidity, and relative humidity.

- Specific enthalpy is the total energy of the combination of dry air and water vapor per unit mass of dry air.

- Specific volume is the volume filled by the combination of dry air and water vapor per unit mass of dry air.

- Vapor pressure is the pressure exerted by a vapor at a given temperature.

- Atmospheric pressure is the pressure within different levels of Earth's atmosphere.

\subsection{Climate zones}

Climate is the statistical average of weather over a long period of time. Climate zone systems have been developed by a various individuals and institutions to categorize regions based on their climate characteristics. The three systems for defining climate zones that were looked at were the (1) Army Facilities Component System (AFCS), (2) American Society of Heating Refrigeration and Air Conditioning Engineers (ASHRAE), and (3) Köppen climate classification systems. Each classification system is intended 
to inform those interested in that system's intended purpose. The AFCS system was developed to inform U.S. Army commanders of conditions that are conducive to safe performance of operational activities (Technical Manual [TM] 5-304). The ASHRAE system was developed for the design of building systems including heating, ventilation, and air conditioning (HVAC) and building envelope (ASHRAE 2013; Halverson et al. 2014). The Köppen system was developed by climatologist Wladimir Köppen, and it is commonly used by the a wide range of disciplines (Peel, Finlayson, and McMahon 2007). This section will focus on the AFCS and ASHRAE systems.

\subsubsection{Army Facilities Component System}

AFCS defines four climate zones and seven climate categories, as shown and described in Table 1 . Each category is defined by ambient air temperature, reverse season air temperature, relative humidity, and solar radiation. Table 1 also shows the temperature and relative humidity for which storage and transit are considered safe. Within the text of this document, each climate category further defines ranges for characteristics such as wind velocities, atmospheric pressure, and snow load. Considerations include labor for operation, material storage, and construction orientation.

Table 1. Summary of temperature, solar radiation, and relative humidity extremes within AFCS climate categories and zones (from TM 5-304).

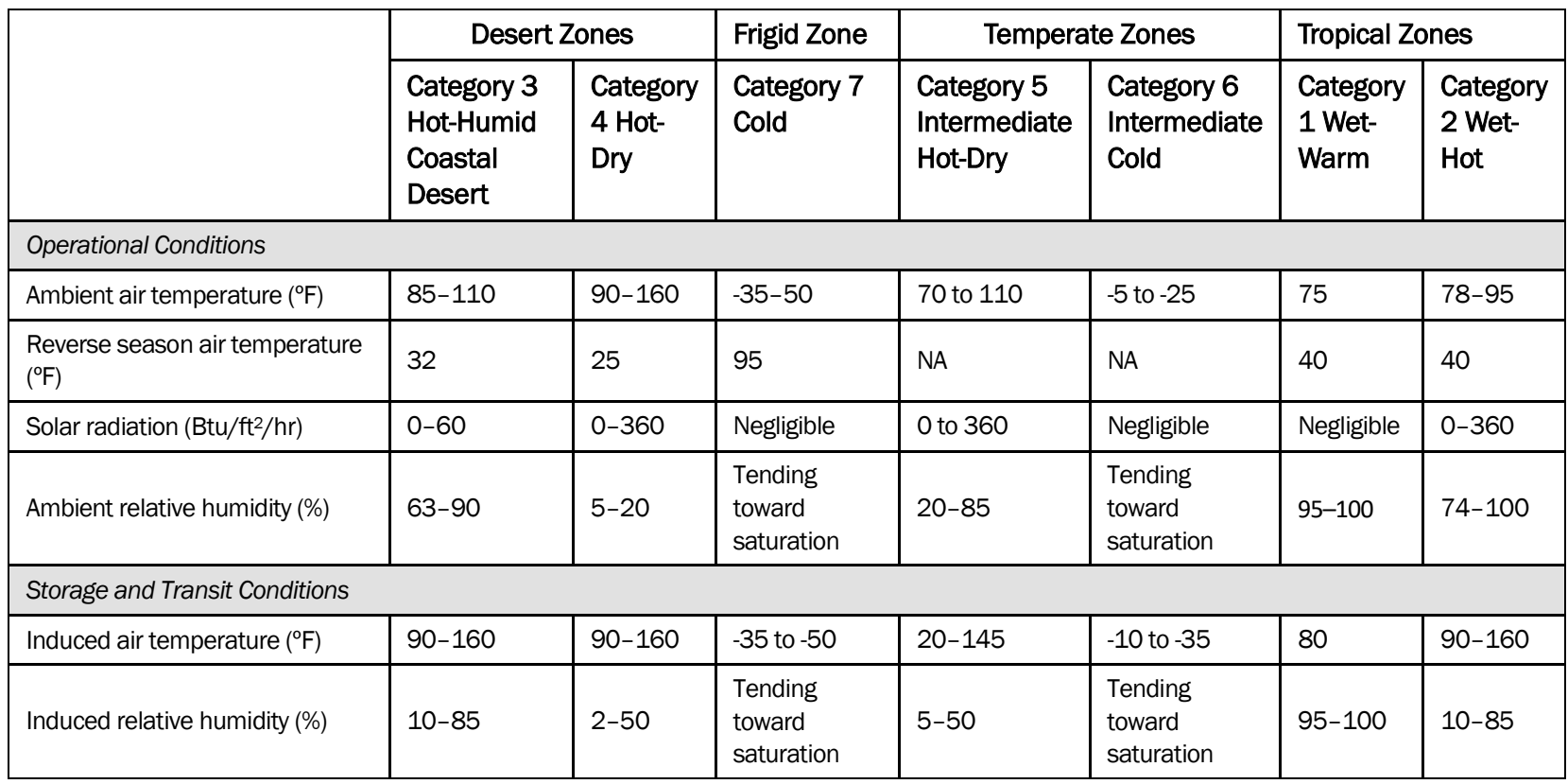




\subsubsection{American Society of Heating, Refrigeration, and Air Conditioning Engineers climate system}

Climate zones using this system can be defined from the heating degree days (HDD) above $18^{\circ} \mathrm{C}$, cooling degree days above $10^{\circ} \mathrm{C}$, monthly mean temperature, and monthly precipitation. Zones are defined by major climate type and a zone number, as shown in Table 2. These zones have been defined and mapped for the United States (ASHRAE 2014; see Figure 1) and for the globe (ASHRAE 2013). The ASHRAE system and regional psychrometric parameters have been used to (a) calculate the heat flow and moisture flow in buildings, and (b) determine the susceptibility of degradation by materials used in building envelopes and building system design (ASHRAE 2014).

Table 2. International climate zone definitions (ICC 2012).

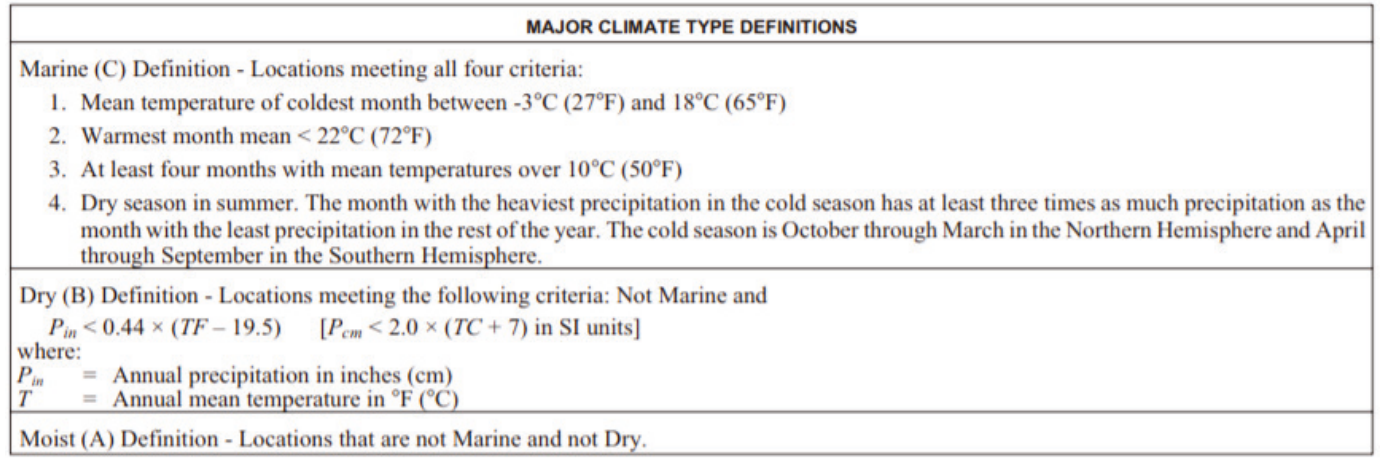

\begin{tabular}{|c|l|l|}
\hline \multirow{2}{*}{$\begin{array}{c}\text { ZONE } \\
\text { NUMBER }\end{array}$} & \multicolumn{2}{|c|}{ THERMAL CRITERIA } \\
\cline { 2 - 3 } IP Units & \multicolumn{1}{|c|}{ SI Units } \\
\hline 1 & $9000<\mathrm{CDD} 50^{\circ} \mathrm{F}$ & $5000<\mathrm{CDD} 10^{\circ} \mathrm{C}$ \\
\hline 2 & $6300<\mathrm{CDD} 50^{\circ} \mathrm{F} \leq 9000$ & $3500<\mathrm{CDD} 10^{\circ} \mathrm{C} \leq 5000$ \\
\hline $3 \mathrm{~A}$ and $3 \mathrm{~B}$ & $\begin{array}{l}4500<\mathrm{CDD} 50^{\circ} \mathrm{F} \leq 6300 \\
\mathrm{AND} \mathrm{HDD} 65^{\circ} \mathrm{F} \leq 5400\end{array}$ & $\begin{array}{l}2500<\mathrm{CDD} 10^{\circ} \mathrm{C} \leq 3500 \\
\text { AND HDD } 18^{\circ} \mathrm{C} \leq 3000\end{array}$ \\
\hline 4A and 4B & $\begin{array}{l}\mathrm{CDD} 50^{\circ} \mathrm{F} \leq 4500 \mathrm{AND} \\
\mathrm{HDD} 65^{\circ} \mathrm{F} \leq 5400\end{array}$ & $\begin{array}{l}\mathrm{CDD} 10^{\circ} \mathrm{C} \leq 2500 \mathrm{AND} \\
\mathrm{HDD} 18^{\circ} \mathrm{C} \leq 3000\end{array}$ \\
\hline $3 \mathrm{C}$ & $\mathrm{HDD} 65^{\circ} \mathrm{F} \leq 3600$ & $\mathrm{HDD} 18^{\circ} \mathrm{C} \leq 2000$ \\
\hline $4 \mathrm{C}$ & $3600<\mathrm{HDD} 65^{\circ} \mathrm{F} \leq 5400$ & $2000<\mathrm{HDD} 18^{\circ} \mathrm{C} \leq 3000$ \\
\hline 5 & $5400<\mathrm{HDD} 65^{\circ} \mathrm{F} \leq 7200$ & $3000<\mathrm{HDD} 18^{\circ} \mathrm{C} \leq 4000$ \\
\hline 6 & $7200<\mathrm{HDD} 65^{\circ} \mathrm{F} \leq 9000$ & $4000<\mathrm{HDD} 18^{\circ} \mathrm{C} \leq 5000$ \\
\hline 7 & $9000<\mathrm{HDD} 65^{\circ} \mathrm{F} \leq 12600$ & $5000<\mathrm{HDD} 18^{\circ} \mathrm{C} \leq 7000$ \\
\hline 8 & $12600<\mathrm{HDD} 65^{\circ} \mathrm{F}$ & $7000<\mathrm{HDD} 18^{\circ} \mathrm{C}$ \\
\hline
\end{tabular}


Figure 1. Climate zone map for the United States (Halverson et al 2014).

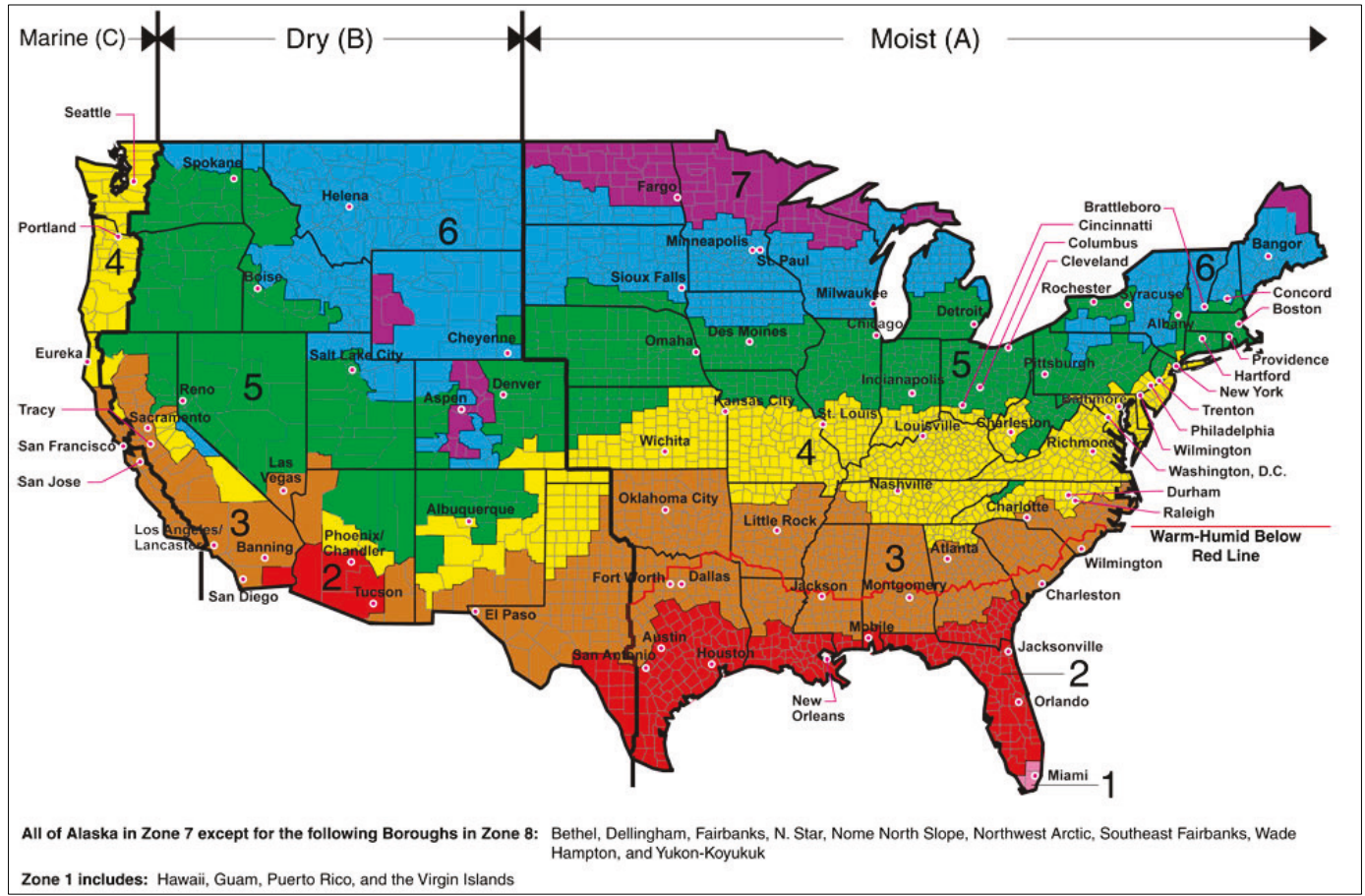




\section{Factors Leading to Material Degradation}

Material degradation will occur if the surrounding air has the right psychrometric properties (as discussed in Chapter 2), and the material has the right physical and chemical properties. Even under the ideal combinations of these factors, materials can withstand short durations of exposure that, if left unchanged, would lead to decay. Therefore, degradation is dependent on (a) the time of exposure to conditions favorable for decay and (b) the physical properties of the exposed material. The sensitivity of a material to specific degradation drivers and the length of exposure required for decay depend on the material type.

\subsection{Mechanisms that cause degradation}

The primary drivers that lead to degradation are temperature, moisture (e.g., humidity, condensation, and rain), solar radiation, pollutants and contaminants, biological agents, and contact between reactive materials. Temperature, moisture, and solar radiation are all used to describe the psychrometric properties of the air and the heat and moisture transport through materials, as discussed in Chapter 2. Decay by pollutants/contaminants, biological agents, and contact between reactive materials are facilitated by biological and chemical processes.

\subsubsection{Temperature, heat, moisture}

Temperature alone does not cause material degradation from many decay mechanisms. When conditions are favorable, the presence of moisture is the primary driver of material degradation in most cases. The psychrometric properties and climate zone (mentioned in chapter 2) of an area of interest can be used to guide decisions on the temperature and expected physical state of the water (i.e., solid, liquid, gas). The air will have a measurable temperature and a measurable humidity (moisture content). If the temperature of a material's surface is equal to the dew-point temperature, then the water vapor in the air will condense and the surface will collect liquid water. This is the reason that drinking cups containing cold water will collect condensation in the summertime. If the DBT approaches the WBT, then the amount of water vapor in the air will increase. This result increases both humidity and vapor pressure in the air. Once the humidity is equal to $100 \%$, the air is fully saturated and the DBT, WBT, and dew- 
point temperature become equal. In other words, any surface temperature below that equalized temperature will collect condensation.

Temperature, as discussed above, is a physical measurement of an object, and it is related to the total movement (kinetic energy) of particles in the object. Heat is the total energy of the motion of particles in an object, and it is dependent on the object's speed of motion plus the size and mass of the object. The transfer of heat energy requires a temperature differential. The transfer of heat always moves from higher temperature to lower temperature, and the heat transfer will continue until the two objects reach the same temperature. The three mechanisms of heat transfer are conduction, convection, and radiation, as explained below:

- Conduction is the transfer of heat by direct molecular contact.

- Convection is the transfer of heat by movement of a gas or liquid.

- Radiation is the transfer of heat by electromagnetic waves.

Moisture can be transferred by two mechanisms: temperature differential and pressure differential. Water vapor can be transferred due to warm moist air moving from a warm medium to a cold medium, or air with higher vapor pressure will move toward air with lower vapor pressure. Liquid water can also move by capillary action from higher pressure to lower pressure in porous media such as brick or CMU blocks.

Different materials and different mechanisms of decay will be present under specific conditions. Which agents determine those specific conditions are material dependent. Moisture acts as a transport mechanism to distribute agents that contribute to material decay, as does temperature. For example, wood will be susceptible to mold growth between moisture ranges of $75 \%-80 \%$ relative humidity and temperatures from $5^{\circ} \mathrm{C}$ to $50^{\circ} \mathrm{C}$. Even though mold spores may still be present, growth does not typically occur outside these temperature ranges (Straub and Burnett 2005). It should be noted, however, that mold spores can survive below freezing and up to $60^{\circ} \mathrm{C}$ and, if conditions become favorable, the surviving spores could initiate mold growth (Straub and Burnett 2005). The presence of moisture is also critical to degradation of metals, concrete, and masonry units. Corrosion in metals, such as steel, is an electrochemical process that occurs in the presence of moisture. 


\subsubsection{Solar radiation}

Radiation can be absorbed, reflected, or transmitted by materials. If the material is opaque (e.g., wood, metals, CMU), solar radiation is primarily absorbed or reflected. If the material is transparent, solar radiation is primarily transmitted. If the material is translucent, solar radiation will undergo all three mechanisms. The percentage by which the radiation is absorbed, reflected, or transmitted is dependent on the material's degree of translucency. Solar radiation that is absorbed causes surface heating, which changes the temperature of that material.

When porous mediums (e.g., brick or CMU) are wetted by rain or water spray, they store water. If the exterior surface is heated by solar radiation, this warming can change the stored water from a liquid to gas (water vapor). If a walled structure is closed (e.g., a building with CMU walls) and one side of the wall is cold and the other side is warm, some of the heated water vapor will move to the colder, less moist air due to the combination of temperature and pressure differentials. The rest of the heated vapor is at a higher pressure, so it moves to the lower pressure, less moist, warm side. If there is a surface that does not allow vapor to flow on the inside surface and food sources (wood or certain types of insulation) are present, then mold may develop (Lstiburek 2001).

Solar radiation sources can cause chemical changes in some materials. Heating by solar radiation can cause cracking in paint and coatings (Kish 2017). Failure of paint and coatings used as a protective layer for metals can lead to corrosion of metals subsequently exposed to the environment (UFC 3-190-06). Photodegredation of plastics weakens the material and is well documented (UNEP 1998).

\subsubsection{Pollutants and contaminants}

The presence of pollutants (natural or introduced substances) and contaminants (introduced substances) can lead to chemical deterioration of operational materials. This type of degradation is facilitated by the presence of moisture. For example, the salinity of the atmospheric moisture and transport of the moist air by prevailing winds in marine climates can affect the rate of corrosion of unprotected steel. For example, higher salinity of the air in marine climates can lead to higher rates of degradation (Alcántara et al. 2017). 
The presence of chlorides from deicing salts and a moisture source can cause efflorescence (crystallization of salt). The presence of salt leads to scaling in concrete materials and corrosion in steel.

\subsubsection{Biological agents}

The most common types of biological agents that cause deterioration in materials are mold spores and insects. These biological agents require a food source such as that provided by building materials. Mold growth can occur in wood and masonry types of construction. Mold growth in masonry can occur if the source provides sufficient nutrients and moisture, from condensation or sufficient humidity. The formation of mold in masonry due to solar driven moisture transport was discussed in section 3.1.2. Insects are most common in wood and some insulation materials (Gibson 2018). Mold growth in wood is discussed in Chapter 4.

\subsubsection{Reactive materials}

When materials that are chemically incompatible are in contact and moisture is also present, then a chemical reaction will occur that causes chemical and physical changes in the materials. For example, when bare aluminum is in contact with cementitious materials (e.g., concrete, mortar, CMUs), creosote, tar, or dissimilar metals (e.g., steel, copper, bronze, and brass) within a structure, then corrosion results and the aluminum must be protected against it. This occurrence of corrosion is especially likely whenever excess moisture is present, especially moisture from salt water. Another example of reactive materials occurs when concrete is in contact with gypsum blocks, gypsum tiles, or gypsum board (drywall), and the presence of excess moisture carries gypsum to concrete or CMU surfaces. The gypsum then causes degradation of the hardened cement paste (cement and water).

\subsection{Chemical and physical properties of materials}

Materials that have a high resistance to material degradation are considered to be durable materials. The durability and sensitivity to degradation are related to the chemical and physical properties of the material. The material's chemical properties include chemical structure and chemical composition, which are related to the material's ability to withstand reactions with pollutants, reactions with adjacent materials, and heating with- 
out chemical changes. The durability performance of a material is dependent on the physical properties of thermal conductivity, permeability, and porosity.

\subsection{Time of exposure}

The most critical factor dictating whether degradation of a specific material will occur is the elapsed time of exposure. If an insufficient time is spent under conditions favorable to a material's decay, then the material will not undergo decay. Also, if conditions change to be unfavorable to decay without returning to favorable conditions for decay, then degradation will not occur. For example the corrosion of metals is dependent on the rate of corrosion, moisture, presence of chlorides and acids, temperature, and the time of wetness (TOW). The TOW is the time spent (in hours) above $80 \%$ relative humidity and above freezing temperature (Straub and Burnett 2005).

Wood, steel, concrete, and CMU are all porous mediums and therefore, they all will have some level of moisture storage capacity. This storage capacity increases the material's time of exposure and susceptibility to decay in the presence of moisture. Materials that are nonporous, such as some plastics and rubbers, may be less susceptible to degradation when they are in the presence of moisture. 


\section{Degradation of Wood}

\subsection{Mechanisms and other factors that cause degradation}

Understanding the mechanisms and other factors that cause degradation in wood is central to understanding the methodology for developing a useful correlation between rate of degradation and wood as a material in structural design.. There are three primary mechanisms that drive the degradation of wood: fungi, insects, and weathering (Shupe, Lebow, and Ring 2008). Each of these mechanisms attack wood in different ways and thus, each mechanism requires a different approach for developing a correlation that relates the mechanism to the rate of wood degradation. This section and subsequent sections in this chapter (4.2 and 4.3) provide the rational basis for the team's research into the degradation of wood.

\subsubsection{Insects and marine borers}

While there are a number of insects that destroy wood, the three most concerning are termites, beetles, and carpenter ants (Shupe, Lebow, and Ring 2008,10 ) Insects degrade wood mechanically by consuming it as food or by boring through it as part of their reproductive cycle (e.g., termites and wood borers, respectively).

In addition to the particular kinds of insects mentioned in the paragraph above, a distinction should also be made regarding the moisture content of the wood they attack. That is to say, among the different species of termites, beetles, and ants, there are certain types that attack either moist or dry wood. This distinction is important in the sense that insects that attack moist wood typically degrade wood in conjunction with fungi, whereas those that attack dry wood do not (Shupe, Lebow, and Ring 2008, 10).

While outside the scope of this report (i.e., outside the use of wooden construction material for land-based structures), it should be noted that another class of organisms, marine borers, also attack wood. These marine borers are not insects, however, but rather mollusks and crustaceans (Shupe, Lebow, and Ring 2008, 10). Marine borers attack wood in saltwater structures, such as wooden pilings and boats (Shupe, Lebow, and Ring 2008, 15). 


\subsubsection{Weathering}

Weathering refers to damage caused by climatic factors such as temperature, moisture, and ultraviolet (UV) radiation (e.g., exposure to sunlight). Degradation from weathering produces surface roughening, checking, splitting, and ultimately, wood cell erosion (Shupe, Lebow, and Ring 2008, 4). Wood cell erosion, however, is a slow process (Shupe, Lebow, and Ring 2008, 4).

\subsubsection{Fungi}

Wood degradation caused by fungi attack represents the majority of the research presented herein. This is because conditions that favor the growth of wood-degrading fungi are overly common. Indeed, nearly all degradation of wood is caused by fungi (Lindgren 1953, 1-6).

There are three categories of wood-degrading fungi: brown rot, white rot, and soft rot (Shupe, Lebow, and Ring 2008, 5). These wood-degrading fungi are classified as such because of their appearance and because they each attack one of the three main components of wood: cellulose, hemicellulose, and lignin (Shupe, Lebow, and Ring 2008, 5). That is to say, all white rot fungi can degrade lignin, but their ability to degrade cellulose and hemicellulose varies; brown rot fungi degrade cellulose and hemicellulose and soft-rot fungi degrade cellulose.

It should also be noted that not all fungi cause wood degradation (Shupe, Lebow, and Ring 2008, 5). Indeed, of the many types of fungi that attack wood, a number are classified as wood-staining or mildew fungi because they discolor rather than degrade the wood (Shupe, Lebow, and Ring 2008,7 ). These types of fungi typically develop because of poor lumberdrying practices or overly wet conditions and do not cause a loss of strength (Shupe, Lebow, and Ring 2008, 8).

\subsection{Environmental factors affecting wood degradation}

In addition to the mechanisms listed in subsections 4.1.1-4.1.3, there are a number of environmental factors that affect the rate of wood degradation. These factors range from the nutrients contained in the wood to its acidity. The following subsections (4.2.1-4.2.6) provide a quick overview of these factors and of their applicability to this study. 


\subsubsection{Nutrients}

Wood-degrading fungi can readily find their basic nutritional requirements in the structural carbohydrates as well as in certain "extraneous materials" in wood (Highley and Kirk 1979, 1151). In addition, nitrogen is chief among the nutrients that increase the rate of degradation caused by wood-degrading fungi (Highley and Kirk 1979, 1154).

\subsubsection{Extraneous compounds}

The hearts of many trees contain compounds that are rich in extractives. These nonstructural constituents include alkaloidal secondary metabolites of trees, terpenes, and a number of phenolic compounds that greatly influence the rate of degradation (Highley and Kirk 1979, 1154). It should be noted that while a number of these extractives encourage the growth of wood-degrading fungi, some of these extractives are toxic to fungi (Highley and Kirk 1979, 1154).

\subsubsection{Temperature}

Most wood-degrading fungi are mesophilic, so they grow optimally in a temperature range of $25^{-} 30^{\circ} \mathrm{C}$ (Highley and Kirk 1979, 1154). While generally unable to grow in temperatures exceeding $40^{\circ} \mathrm{C}$, there are some species of wood-degrading fungi that can tolerate and grow optimally in temperatures higher than $40^{\circ} \mathrm{C}$. All these temperature ranges can be found in the majority of locations in which the USG operates.

\subsubsection{Acidity}

The $\mathrm{pH}$ of wood is controlled by the presence of volatile acids, most notably acetic and formic acids. The $\mathrm{pH}$ of hardwoods is generally in the range of 2.8 to 6.8 , and the $\mathrm{pH}$ of softwoods is generally in the range of 2.7 to 8.8 , with the optimal $\mathrm{pH}$ range for wood-degrading fungi being in the range of 3.5 to approximately 6.0 (Highley and Kirk 1979, 1154).

\subsubsection{Oxygen and carbon dioxide}

Wood-degrading fungi thrive at different levels of $\mathrm{CO}_{2}$; white and brown rot fungi, for example, thrive in a near-anaerobic atmosphere with high levels of $\mathrm{CO}_{2}$. Thus, the growth of wood decaying fungi is aided by higher levels of $\mathrm{CO}_{2}$ and hindered by lower levels of $\mathrm{O}_{2}$ (Highley and Kirk 1979, 
1154 and 1155). Additionally, high levels of $\mathrm{CO}_{2}$ stimulate spore germination (Morton and French 1974), whereas removal of $\mathrm{CO}_{2}$ prevented germination (Highley and Kirk 1979, 1155).

\subsubsection{Moisture}

The moisture content of trees has a dramatic effect on their rate of degradation. Within a certain range of moisture content (generally 20\%-30\%), a wetter tree will have a greater rate of decay.

\subsubsection{Microorganisms}

Wood-degrading fungi generally grow alongside other microorganisms. The microoganisms, however, have a number of different interactions with wood-degrading fungi. That is to say, microorganisms can have a direct or indirect influence and can either enhance or hinder the degradation rate initiated by fungi (Highley and Kirk 1979, 1155).

\subsection{Predictive methods for degradation of wood}

At the time of this writing, no correlations exist for relating a wood degradation index to damage caused by insect attack or weathering. With regard to weathering (i.e., damage leading to wood cell erosion), the lack of literature relating it to some sort of degradation index indicates that its effects are negligible. Indeed, as mentioned in the previous sections, degradation caused by weathering is a slow process (Shupe, Lebow, and Ring 2008, 4). As for insect attack, there are a number of maps relating the probability of insect damage to geographic location (example in Figure 2). Unfortunately, these maps are generally limited to the United States and other developed nations (e.g., Australia). Considering that these maps are limited to areas that are outside locations where the USG typically operates, there is, at present, little that can be done to create a wood degradation index that is both rational and useful with the currently available data. Again, the majority of work in this study is focused on damage caused by fungi attack. 
Figure 2. Sample termite hazard map (Cookson and Trajstman 2002, 34).

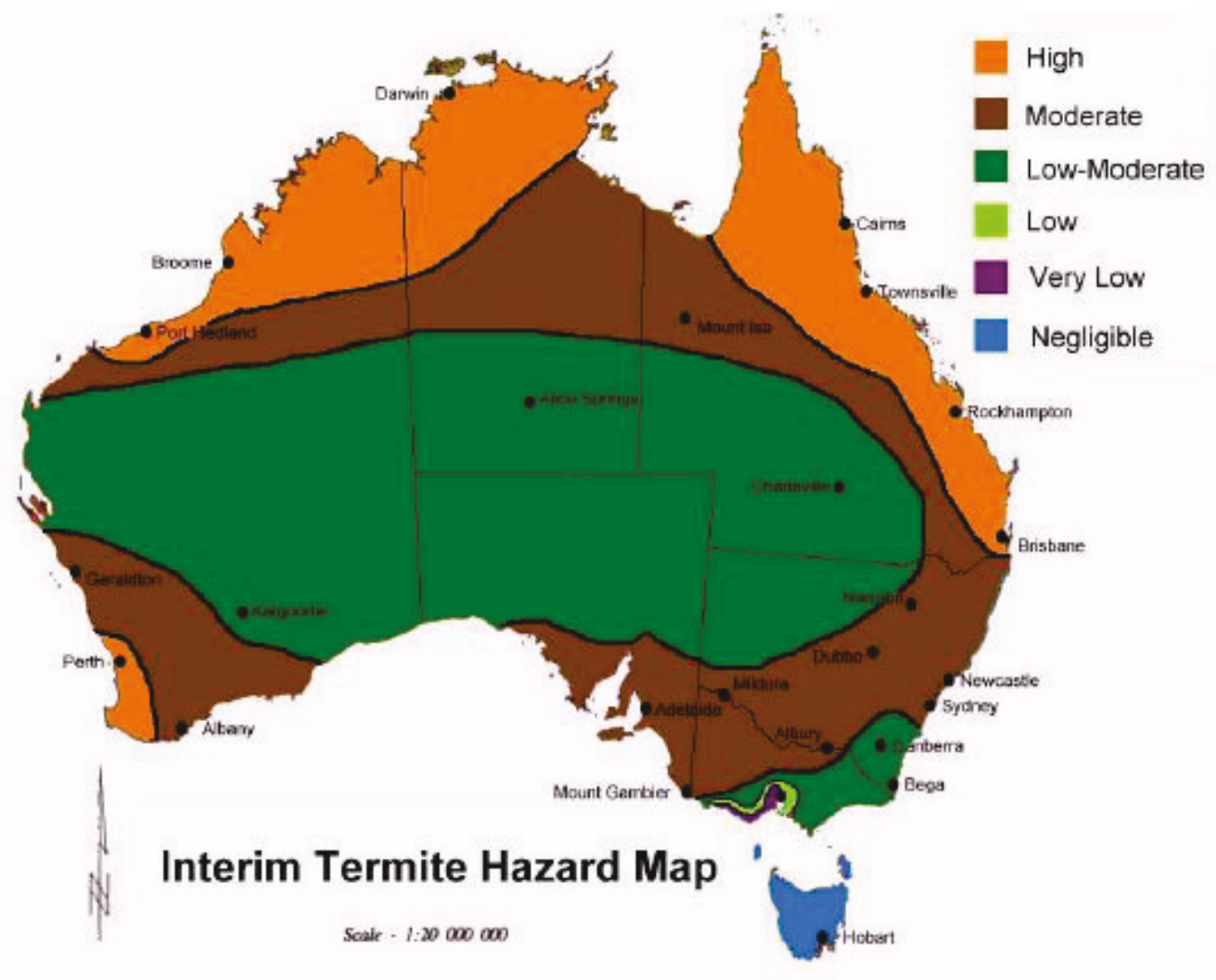

\subsubsection{Development of a climate index by Scheffer (1971)}

The climate index (also referred to as the Scheffer Index herein) is the basis for a number of degradation-hazard indices that are currently used. Thus, it is described in detail here since it is central and relevant to this work. Indeed, there are variations of the Scheffer Index being currently being developed in the United States and other developed countries (Fernandez-Golfin et al. 2016; Carll 2009).

The Scheffer Index was developed by Scheffer $(1971,26)$ to respond to an increasing awareness at the time that "protective measures for wood-particularly preservative treatments-must relate to climate objectively". That is to say, Scheffer posited that the savings gained by using wood for construction were negated if the wood was not adequately protected against degradation. Indeed, this concern was shared by the Department of Navy, which also expressed a need for a rational basis to quantify the problem (Scheffer 1971, 26). 
To address this concern, Scheffer developed a concise formula based on standard weather data that could be used to estimate the degradation hazard for wood used above ground. He based the Scheffer Index on the following four criteria (Scheffer 1971, 6):

1. That the index correlates with degradation rates measured experimentally in different climates and with rates seen by practitioners.

2. That the climatological data used in the correlation be readily available from the National Weather Service [referred to in 1971 as U.S. Weather Bureau].

3. That the correlation minimize the number of parameters used for calculation.

4. That the index be in the range of $0-100$ for most climates in the United States.

\subsubsection{Temperature effects}

Scheffer (1971) conducted analyses of typical growth-temperature curves for a number of commonly occurring wood-degrading fungi and determined that a temperature factor could be developed by subtracting $35^{\circ} \mathrm{F}$ from the mean monthly temperature. Scheffer (1971) based this assertation on the following three trends obtained from Figure 3:

1. Fungi growth is limited to temperatures above $35^{\circ} \mathrm{F}$.

2. Fungi growth rate can be estimated as linear from a temperature of $35^{\circ} \mathrm{F}$ to nearly the optimum growth temperature.

3. As a corollary to the preceding item, the rate of degradation caused by fungi is proportional to the number of degrees that temperature exceeds $35^{\circ} \mathrm{F}$ (i.e., actual temperature minus $35^{\circ} \mathrm{F}$ ). 
Figure 3. Growth rate of Lenzites trabea and Polyporus versicolor (from Scheffer 1971, 27).

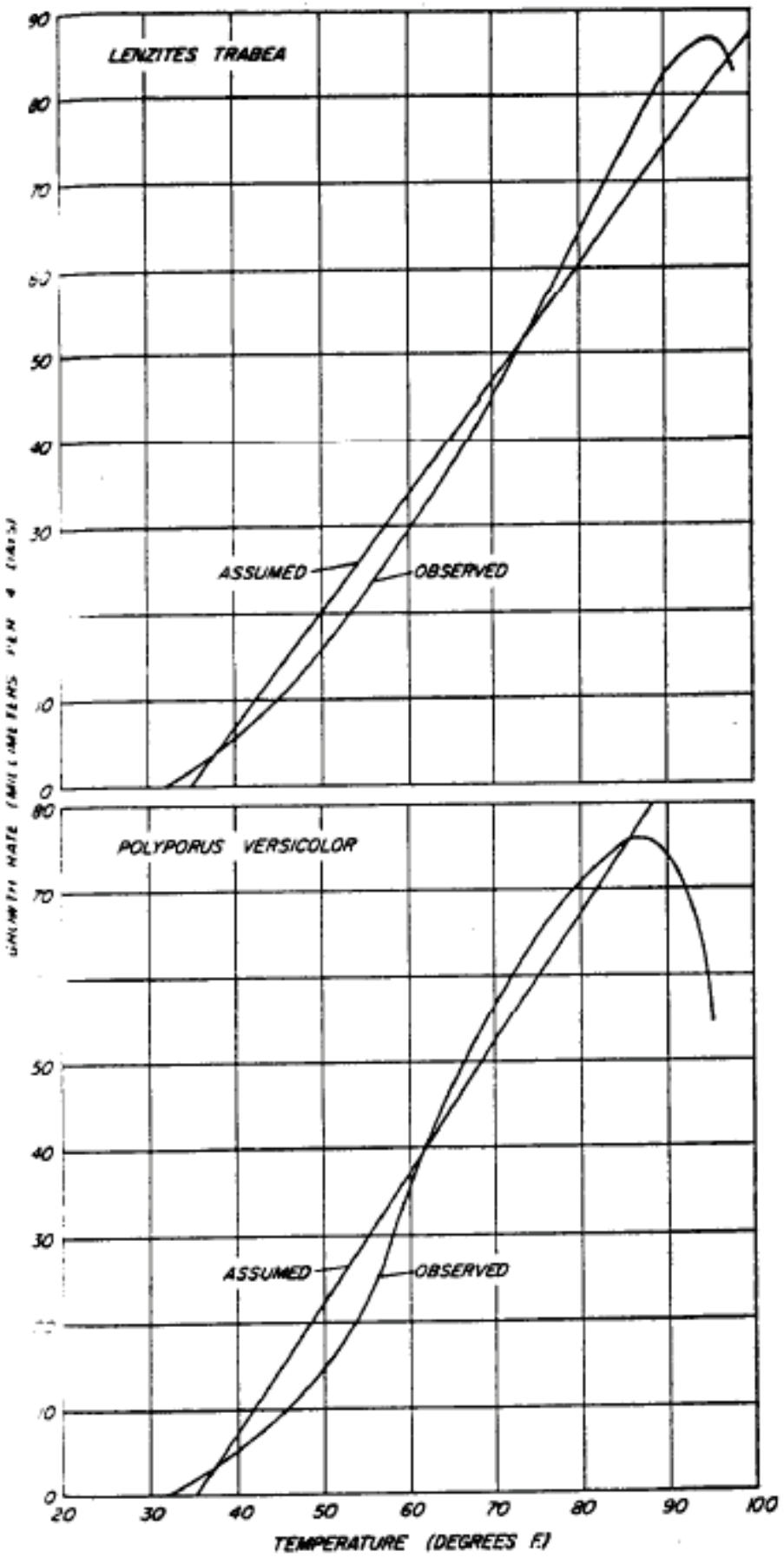

It should be noted that modeling the growth rate as linear is a simplification of the data, and Scheffer (1971) noted this simplification could cause errors at temperatures above $85^{\circ} \mathrm{F}$. Scheffer $(1971,26)$ also noted, however, that: 
This discrepancy should not be of practical consequence, however, because mean monthly air temperatures generally do not significantly exceed $85{ }^{\circ} \mathrm{F}$ except in the warmest tropical ares and in arid or semiarid regions-where lack of moisture rather than the higher temperatures would be controlling in the index formula.

\subsubsection{Moisture effects}

Scheffer (1971) also saw the need to incorporate a moisture factor into the correlation because the moisture content of wood greatly impacts the growth rate of fungi. Through trial and error, Scheffer $(1971,27)$ found the best correlation of fungi growth to be the mean number of days per month with 0.01 in. or more of precipitation. Additionally, Scheffer opted to arbitrarily subtract 3 days from the mean to keep the index near o for drier regions (e.g., the Southwest region of the United States).

\subsubsection{Scheffer Index}

Scheffer (1971) proposed the following equation:

$$
C I=\frac{\sum_{J a n}^{D e c} \cdot[(T-2)(D-3)]}{30}
$$

where:

$C I=$ climate index $T=$ mean montly temperature in ${ }^{\circ} \mathrm{F}$, and $D=$ number of days in the month with $0.01 \mathrm{in}$. or more of precipitation.

Using the Scheffer Index, Scheffer (1971) was able to create a climate index (CI) map of the conterminous United States (Figure 4), with boundaries that delineated:

- least favorable conditions for decay $(C I<35)$,

- intermediately favorable conditions for decay $(35 \leq C I \leq 65)$, and

- most favorable conditions for decay $(C I>65)$. 
Figure 4. Scheffer Index, map of the conterminous United States (from Scheffer 1971, 29).

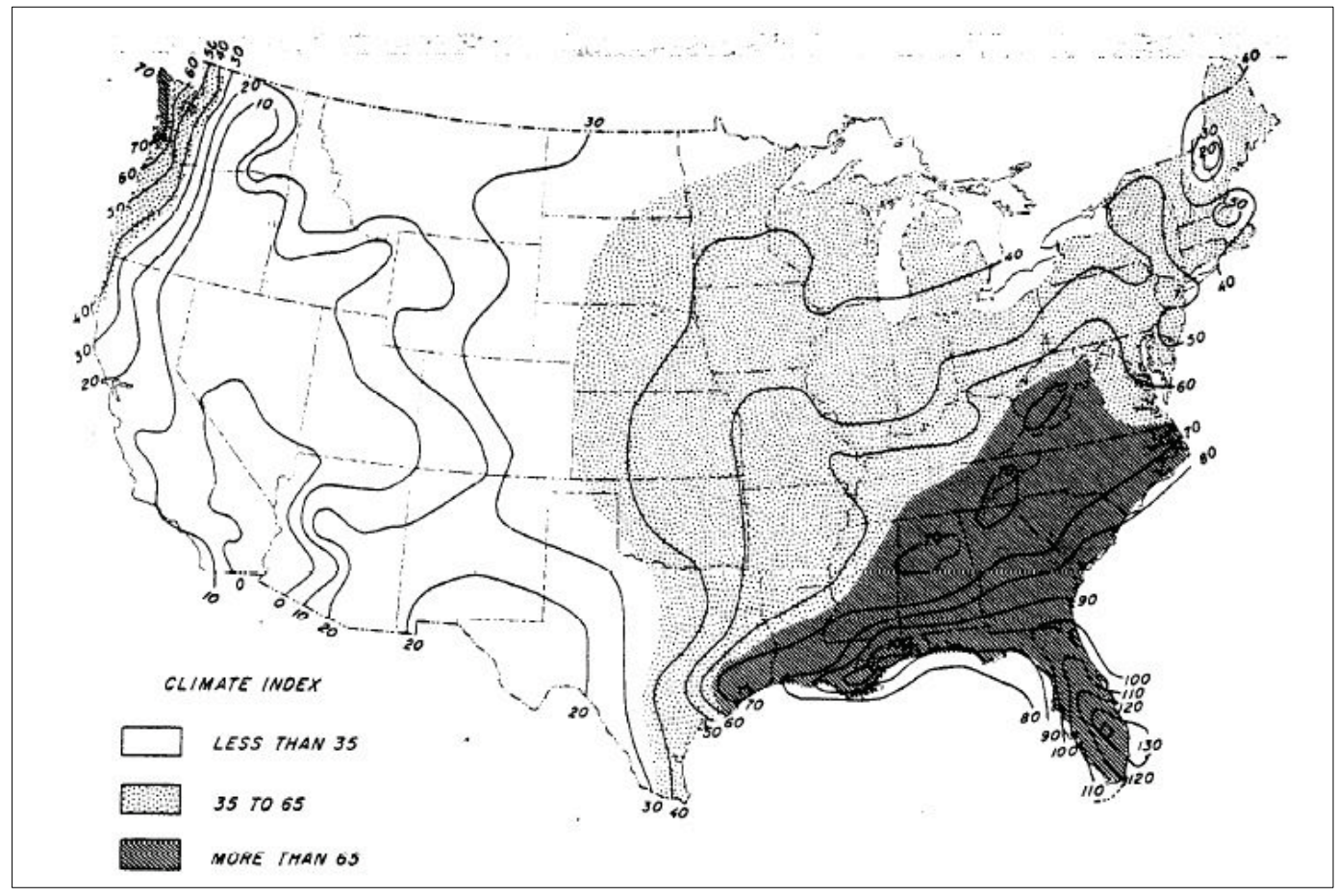

\subsubsection{Experimental verification of the Scheffer Index}

Scheffer (1971) confirmed the veracity of the Scheffer Index by testing two different types of structures, a post and rail unit and a flooring board unit, in three different locations. The experiment featured 2 each of the post and rail and flooring board structures at each location. Of these four structures, one of each type was treated with a wood preservative, and the other was left untreated. All these units were exposed to the elements in Corvallis, Oregon; Madison, Wisconsin; and Gulfport, Mississippi.

Scheffer determined the rate of decay for the untreated structure at each location by plotting the amount of decay over time. These rates were then compared to each other to obtain a relative rate of decay, and these relative rates of decay were compared to the Scheffer Index. Thus, for the Scheffer Index to be a successful estimate of the degradation hazard, the relative rates of decay should be relatively equal to the Scheffer Index at each site.

Scheffer found the rates of decay for the Wisconsin, Oregon, and Mississippi sites to be, respectively, 1.o, 1.0, and 1.9 for the post-rail unit, and 1.0, 1.0, and 2.5 for the flooring unit. Scheffer found the relative values of 
Scheffer Index at the Wisconsin, Oregon, and Mississippi sites to be 1.0, 1.0, and 2.5, respectively. Comparing the experimental values with the estimated values and finding them to match, Scheffer concluded the index to be a reasonable model (Scheffer 1971).

\subsubsection{Development of a decay rate estimation}

Wang, Leicester, and Nguyen (2008) developed a model to estimate the service life of wooden structures above ground. While the ultimate goal of the study was different than that of the Scheffer Index, a portion of the model from Wang et al. (2008) is similar to the efforts of Scheffer (1971). As part of the calculation of service life, Wang et al. used a climate parameter, $k_{\text {climate, }}$ which is defined in the following equation:

$$
k_{\text {climate }}=0.15 \sqrt{t_{\text {rain }}}
$$

where

$t_{\text {rain }}=$ number of days per year with measurable precipitation.

This $k_{\text {climate }}$ climate parameter, then, indicates the level of degradation hazard.

It is interesting to note, as Carll $(2009,2)$ points out, that $k_{\text {climate }}$ is similar in concept to the Scheffer Index. That is, the parameter $t_{\text {rain }}$ is similar to the $D$ term in the Scheffer Index (refer to Eq. 1). Additionally, as Carll $(2009,2)$ points out, plotting isopleths over Australia using $k_{\text {climate }}$ or $C I$ also yields similar results (Figure 5 and Figure 6). 
Figure 5. Degradation hazard map for wooden structures above ground, using $k_{\text {climate }}$ (Wang, Leicester, and Nguyen 2008, 44).

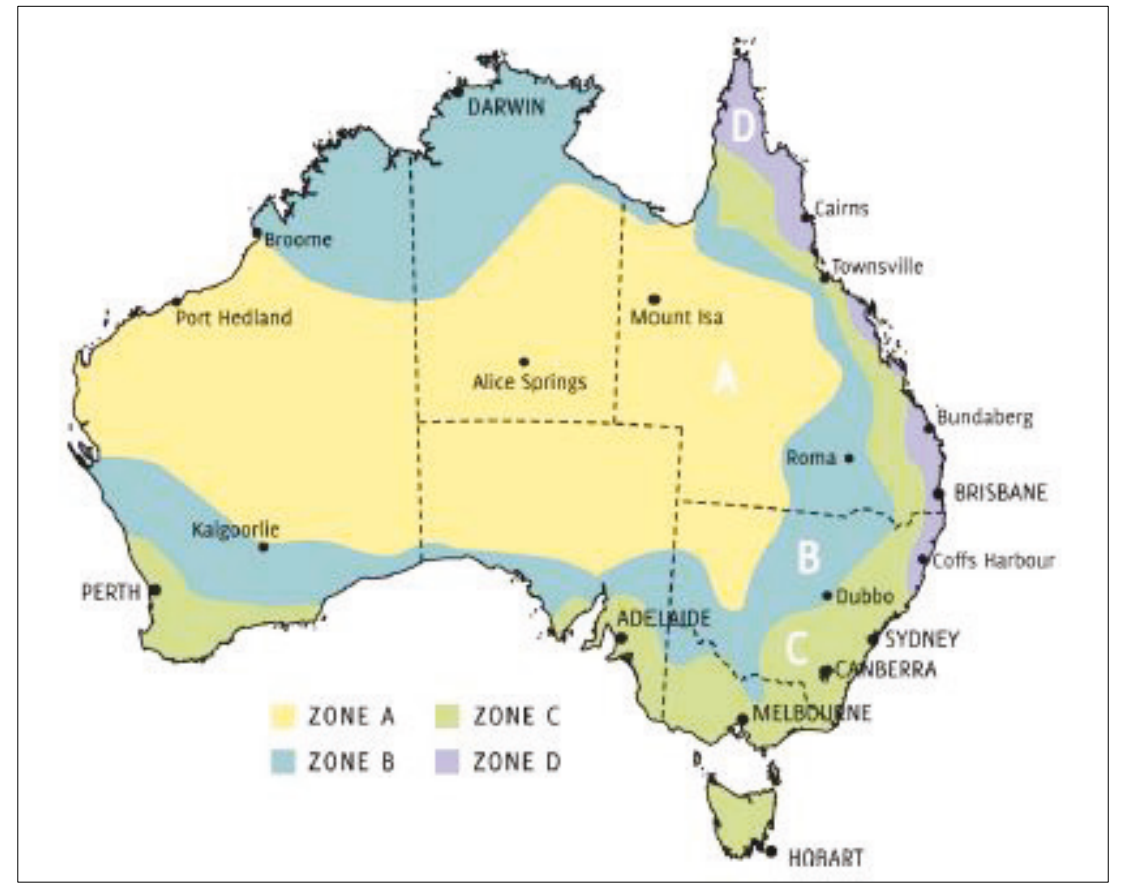

Figure 6. Degradation hazard map for wooden structures above ground, using the Scheffer Index (Wang, Leicester, and Nguyen 2008, 44).

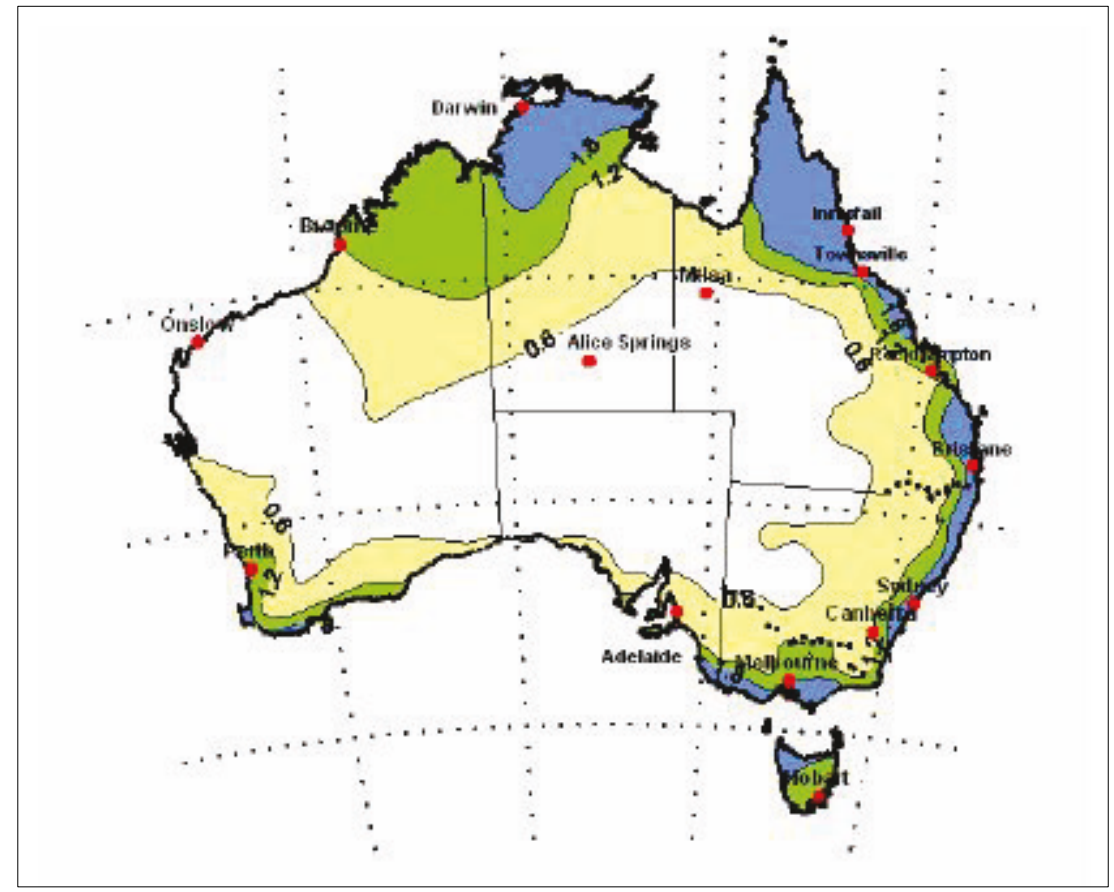




\subsubsection{Implications of the work of Wang et al. (2008)}

The $k_{\text {climate }}$ parameter represents a simpler calculation when compared to the Scheffer Index. While simpler, the $k_{\text {climate }}$ parameter is representative only of the climate found in Australia (Carll 2009), pg. 3. This is because the climate in Australia does not have the same climatic extremes as does the U.S. climate. Thus, in the context of this study, the Scheffer Index may be more applicable to locations worldwide while still providing a reasonable estimation of degradation hazard.

\subsubsection{An update to the Scheffer Index by Fernandez-Golfin et al. (2016) and implications}

Fernandez-Golfin et al. (2016) proposed an update to the Scheffer Index by including additional parameters in the calculation of the climate index. Fernandez-Golfin et al. (2016) proposed the following equation:

$$
C I=\frac{\sum_{J a n .}^{D e c} \cdot\{(T-2)[(D+N * C)-3]\}}{16.7}
$$

where:

$C I=$ climate index,

$T=$ mean monthly temperature in ${ }^{\circ} \mathrm{C}$,

$D=$ number of days in the month with $0.2 \mathrm{~mm}$ or more of precipitation,

$C=$ number of days in month when surface condensation is present, and

$N=$ weighting factor.

In addition to their proposed equation, Fernandez-Golfin et al. (2016) also redefine the risk categories originally proposed by Scheffer (1971). These risk categories are presented in Table 3 .

Table 3. Decay risk (from Fernandez-Golfin, et al. 2016, 597).

\begin{tabular}{ll} 
Climate Index & Decay Risk \\
\hline $0-35$ & Low \\
$36-70$ & Medium \\
$71-100$ & High \\
$>100$ & Extreme
\end{tabular}


From the results presented by Fernandez-Golfin et al. (2016), it is unclear whether the additional parameters add much value to the Scheffer Index. Indeed, Scheffer (1971) suggests that the correlation can be modified-albeit in the context of wood in contact with the ground-to suit the locality and even provides a suggestion for doing so. Thus, without a comparison of a simpler means of modifying the Scheffer Index versus the modification proposed by Fernandez-Golfin et al. (2016), there can be no final decision. Considering these factors, the introduction of the $C$ and $N$ parameters does not fit into the needs of this study for more practical reasons. That is to say, the additional parameters require more data which may not be available in the locations that the USG might operate in.

\subsubsection{An update to the Scheffer Index by Carll (2009)}

Carll (2009) updated the original isopleth map from Scheffer (1971) by using climate normal data. Climate normal data is defined as the "average of a particular climate variable over a uniform and relatively long period of at least three consecutive 10-year periods" (Carll 2009, 3). While Carll's work does not explicitly affect the work of this study, it does acknowledge that the degradation hazard in the conterminous United States has changed during the period from 1971-2000 (Carll 2009). 


\section{Degradation of Concrete Masonry Units}

\subsection{Mechanisms that cause degradation}

Although not discussed in detail here, it is known that CMUs will degrade similar to concrete. There is extensive knowledge about the forms of degradation in concrete (Ratay 2005; Portland Cement Association 2002). Degradation factors for concrete include the following:

- defects present due to chemical and physical changes at time of placement

- chemical incompatibility between the paste (cement and water) and aggregate (rocks and sand)

- efflorescence (soluble salt crystallization)

- deicer scaling

- carbonation

- corrosion of reinforcement and anchors

- fire damage

- freeze-thaw cycles

The degradation mechanisms that are due to environmental factors are efflorescence, deicer scaling, reinforcement corrosion, fire damage, and freeze-thaw damage. Other decay mechanisms can be avoided with proper mixing practices or consideration of environmental factors at time of placement. Efflorescence, deicer scaling, and reinforcement corrosion require the presence of a salt and a water source. This condition can occur due to natural salt in the air or in the surrounding soil, as well as in the presence of deicing salts. Research into the correlation between climatic factors and CMUs to estimate degradation hazard for CMUs is much smaller in scope than for wood.

As opposed to wood, for which there are a large number of mechanisms and factors related to climate that cause degradation, the only climatic factor of degradation for CMU is the freeze-thaw cycle. The term "freeze-thaw cycle" refers to repeated instances of water infiltrating cracks in CMU, and then freezing and expanding. Thus, these repeated cycles initiate larger cracks.

Although not a detrimental degradation factor in most cases, CMU construction can develop mold. Mold is a health concern, because it can affect 
the health and wellbeing of those who come in contact. Currently, the occurrence of mold in CMU is understood (Lstiburek 2001), but an exclusive predictive model is not well documented for mold in a CMU that is based on climatic factors.

\subsection{Predictive methods for the freeze-thaw degradation of CMUs}

Most research papers focus on testing the durability of concrete mixtures based on common test procedures (ASTM C 666/C 666M-03 2008). At present "no specific correlation between moisture absorption, compressive strength, and freeze/thaw susceptibility has been established for concrete unit masonry" (Boothby and Bakis 2008, 308). From the limited literature available, it was apparent that the experimental data was dissimilar to field conditions (e.g., Wawrzenczyk and Molendowska 2017; Janssen and Snyder 1994). For example, the literature showed failure occurring in the ranges of approximately 50-200 freeze-thaw cycles for samples soaked in water. However in some field locations, 200 freeze-thaw cycles can occur in just a few years. It should be noted that in most cases, freeze-thaw damage does not occur in properly designed CMU structures, so CMU structures generally have a life span of several decades.

One avenue of promising research is investigating the potential correlation between weathering damage of concrete and climate zone. The International Residential Code describes the weathering probability for concrete within the United States as negligible, moderate, or severe, and it maps those probabilities (Figure 7). This map is based on actual occurrences for weathering of concrete. As expected, it appears from Figure 7 that there is a correlation between climate zones and concrete's susceptibility to weathering. However, further study would have to be done to confirm this conclusion, and conducting a separate study to develop correlations involving CMUs is outside the scope of this current project. 
Figure 7. Weathering probability of concrete (IRC 2015).

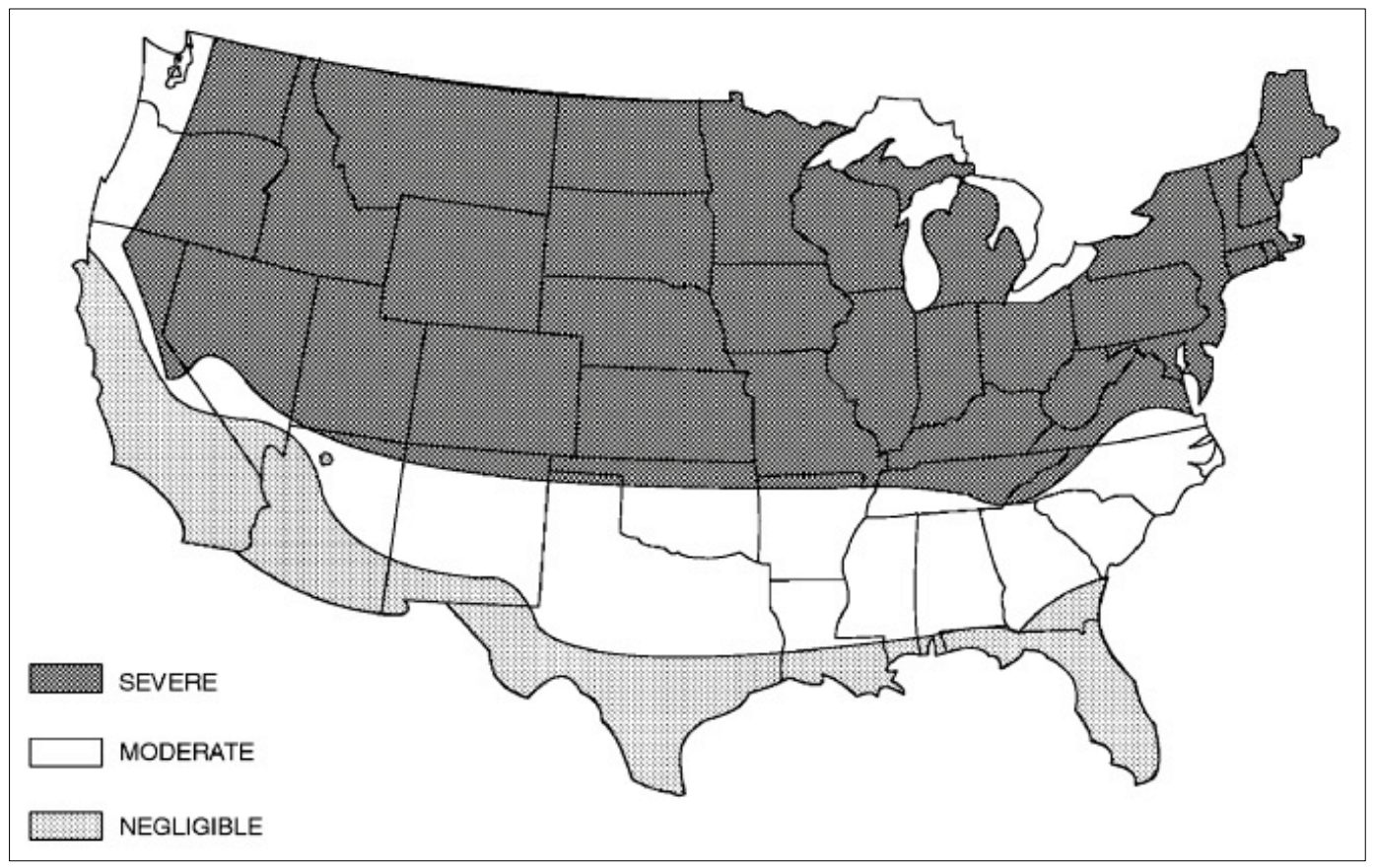

Note 1: Alaska and Hawaii are classified as severe and negligible, respectively.

Note 2: Lines defining areas are approximate only. Local conditions may be more or less severe than indicated by region classification. A severe classification is where weather conditions result in significant snowfall combined with extended periods during which there is little or no natural thawing causing deicing salts to be used extensively 


\section{Conclusions}

This report summarized the general knowledge required to understand and develop a remote assessment of material degradation using GIS-based software. The background topic areas provided were:

- Psychrometric properties of moist air (Chapter 2)

- Climate zones (Chapter 2)

- Mechanisms and factors that affect material decay (Chapter 3)

- Material properties that affect degradation (Chapter 3)

Following that, the degradation factors and potential predictive methods for wood and concrete were researched. Chapter 4 discussed the degradation of wood focusing on mold growth and insect infestation. Chapter 5 discussed the degradation of concrete masonry blocks, focusing specifically on degradation due to freezing and thawing. The prediction of wood degradation by means of weathering has been described by the Shaffer Index. This method is well documented and has been developed by the military (Navy), so it is therefore recommended as the index to be used in the remote assessment of wood. In the case of CMUs there is little research on predictive methods, since proper design and construction practices typically lead to durable construction. However, if regulations on construction are not imposed, then it may be possible to see degradation due to either freeze-thaw cycles or mold growth. The visual similarity between ASHRAE maps of climate zones (e.g., Figure 1) and the IRC map of weathering probability of concrete (Figure 7) shows promise for future development of a predictive model. Therefore, it is recommended that this topic be studied in future efforts. 


\section{References}

Alcántara, Jenifer, Daniel de la Fuente, Belén Chico, Joaquín Simancas, Iván Díaz, and Manuel Morcillo. 2017. "Marine Atmospheric Corrosion of Carbon Steel: A Review." Materials 10(4): 406. https://doi.org/10.3390/ma10040406.

ASHRAE Standard 169. 2013. "Climatic Data for Building Design Standards.” Atlanta, GA: American Society of Heating Ventilation and Air Conditioning Engineers.

ASTM C 666/C 666M-15. 2015 (reapproved). "Standard Test Method for Resistance of Concrete to Rapid Freezing and Thawing 1." West Conshohocken, PA: ASTM International.

Boothby, T.E., C.E. Bakis. 2008. Durability of Externally Bonded Fiber-Reinforced Polymer (FRP) Composite Systems. In Strengthening and Rehabilitation of Civil Infrastructures Using Fibre-Reinforced Polymer (FRP) Composites, edited by L.C. Hollaway and J.G. Teng, 262-316. Boca Raton, FL: CRC Press.

Carll, Charles G. 2009. Decay Hazard (Scheffer) Index Values Calculated from 19712000 Climate Normal Data. General technical report FPL-GTR-179. Madison, WI: U.S. Department of Agriculture, Forest Service, Forest Products Laboratory.

Cookson, L.H. and A.C. Trajstman. 2002. Termite Survey Hazard Mapping. Technical Report 137, CSIRO Forestry and Forestry Products. Clayton South, Victoria (Australia): FWPRDC/CSIRO.

Fernandez-Golfin, Juan, Enrique Larrumbide, Antonio Ruano, Jorge Galvan, and Maria Conde. 2016. "Wood Decay Hazard in Spain Using the Scheffer Index: Proposal for an Improvement." European Journal of Wood and Wood Products 74 (4). Springer Berlin Heidelberg: 591-99.

Gibson, Scott. 2018. “Coping With Termites and Carpenter Ants.” Green Building Advisor. http://www.greenbuildingadvisor.com.

Halverson, M, M.Rosenberg, W.Wang, J. Zhang, V. Mendon, R. Athalye, Y Xie, and R.Hart (Standards Group 90). 2014. Determination of Energy Savings: Quantitative Analysis. ANSI/ASHRAE/IES Standard 90.1-2013. Atlanta, GA: American Society of Heating Ventilation and Air Conditioning Engineers.

Highley, T.A., and T.K. Kirk. 1979. "Mechanisms of Wood Decay and the Unique Features of Heart Rots.” Phytopathology 69(10): 1151-1157.

ICC. 2012. “2012 International Energy Conservation Code.” In International Code, Vol. 1. Washington, DC: International Code Council.

IRC. 2015. 2015 International Residential Code for One- and Two-Family Dwellings and Significant Changes to the 2015 International Residential Code. Boston, MA: Cengage Learning.

ISO 9224. 2012. Corrosion of Metals and Alloys - Corrosivity of Atmospheres - Guiding Values for the Corrosivity Categories. Geneva Switzerland: International Organization of Standards. 
Janssen, D.J., and M.B. Snyder. 1994. Resistance of Concrete to Freezing and Thawing. Report SHRP-C-391. Washington, DC: National Research Council, Strategic Highway Research Program.

Kish, Rich. 2017. "Polymer and Coating Degradation - A Practical Approach to Accelerated Testing." In ABRAFATI 2017, 11; International Coatings Congress and Exhibition of Coatings Industry Suppliers held 3-5 October in Sao Paulo, Brazil. Troy, MI: Paint \& Coatings Industry.

Lindgren, R.M. 1953. “An Overall Look at Wood Deterioration.” Presented at Northeastern Wood Preservation Conference. New Haven, CT: Madison Branch of the Division of Forest Pathology.

Lstiburek, Joseph. 2001. "Solar Driven Moisture in Brick Veneer.” Research Report (RR) RR-0104. Westford, MA: Building Science Corporation https://buildingscience.com/documents/reports/rr-0104-solar-driven-moisture-in-brickveneer/view.

Machine Applications Corporation. 1999. The MAC Humidity/Moisture Handbook. Sandusky, OH: Machine Applications Corporation.

Morton, H.L. and D.W. French. 1974. "Stimulation of Germination of Polyphorus drophilus Basidospores by Carbon Dioxide.” Phytopathology 64: 153-154. doi: 10.1094/Phyto-64-153.

Peel, M. C., B. L. Finlayson, and T. A. McMahon. 2007. "Updated World Map of the Köppen-Geiger Climate Classification.” Hydrology and Earth System Sciences 11 (5): 1633-44. https://doi.org/10.5194/hess-11-1633-2007.

PNNL (Pacific Northwest National Laboratory). 2014. "Determination of Energy Savings : Quantitative Analysis." Based on ANSI/ASHRAE/IES Standard 90.1-2013. Prepared for the U.S. Department of Energy under Contract DE-ACo576RL01830. Richland, WA: Pacific Northwest National Laboratory.

Portland Cement Association (PCA). 2002. "Types and Causes of Concrete Deterioration." PCA R\&D Serial No. 2617. Skokie, IL: PCA.

Ratay, Robert T. 2005. Structural Condition Assessment. Hoboken, NJ: John Wiley and Sons.

Scheffer, T.C. 1971. "A Climate Index for Estimating Potential for Decay in Wood Structures above Ground.” Forest Products Journal 21(10): 25-31.

Shupe, Todd, Stan Lebow, and Dennis Ring. 2008. Causes and Control of Wood Decay, Degradation, and Stain. Miscellaneous publication. Baton Rouge, LA: Louisiana Cooperative Extension Service, Louisiana State University.

Straub, J., and E.F. P. Burnett. 2005. Building Science for Building Enclosures. Westford, MA: Building Science Press.

TM 5-304. 1990. “Army Facilities Components System User.” Washington, DC: Headquarters, Department of the Army. 
UFC 3-190-06. 2004. Protective Coatings and Paints. Washington, DC: Department of Defense. https://www.wbdg.org/ffc/dod/unified-facilities-criteria-ufc/ufc-3-190-06.

UNEP. 1998. Environmental Effects of Ozone Depletion: 1998 Assessment. United Nations Environmental Programme. Vol. 46. https://doi.org/10.1016/S10111344(98)00195-X.

Wang, C.H., R.H. Leicaster, and M.N. Nguyen. 2008. Decay above Ground. Technical manual. Melbourne, Australia: Forest and Wood Products Australia.

Wawrzeńczyk, Jerzy, and Agnieszka Molendowska. 2017. "Evaluation of Concrete Resistance to Freeze-thaw based on Probabilistic Analysis of Damage.” Procedia Engineering 193(2017): 35-41. doi:10.1016/j.proeng.2017.06.183. 


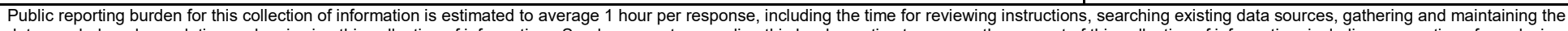

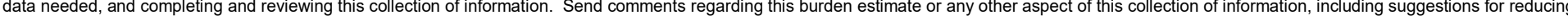

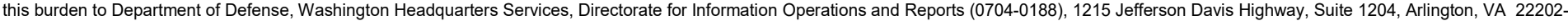

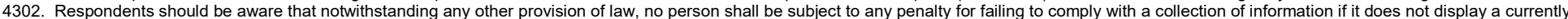
valid OMB control number. PLEASE DO NOT RETURN YOUR FORM TO THE ABOVE ADDRESS.

\begin{tabular}{l|l|l}
\hline 1. REPORT DATE (DD-MM-YYYY) & 2. REPORT TYPE & 3. DATES COVERED (FrOm - To)
\end{tabular}

\section{TITLE AND SUBTITLE \\ September 2018}

Final

Methods of Analysis to Remotely Determine Material Degradation

\section{5a. CONTRACT NUMBER}

5b. GRANT NUMBER

\section{5c. PROGRAM ELEMENT NUMBER}

$\mathrm{T} 45$

6. AUTHOR(S)

Eric L. Kreiger, Joseph A. Gamez, Patrick J. Guertin, and George W. Calfas

\section{5d. PROJECT NUMBER}

455009

5e. TASK NUMBER

\section{5f. WORK UNIT NUMBER}

\section{PERFORMING ORGANIZATION NAME(S) AND ADDRESS(ES)}

U.S. Army Engineer Research and Development Center (ERDC)

Construction Engineering Research Laboratory (CERL)

PO Box 9005

Champaign, IL 61826-9005

\section{PERFORMING ORGANIZATION REPORT NUMBER}

ERDC/CERL TR-18-24

\section{SPONSORING / MONITORING AGENCY NAME(S) AND ADDRESS(ES)}

Assistant Secretary of the Army for Acquisition, Logistics and Technology

103 Army Pentagon

Washington, DC 20314-100

10. SPONSOR/MONITOR'S ACRONYM(S)

ASA(ALT)

11. SPONSOR/MONITOR'S REPORT NUMBER(S)

\section{DISTRIBUTION / AVAILABILITY STATEMENT}

Approved for public release. Distribution is unlimited.

\section{SUPPLEMENTARY NOTES}

\section{ABSTRACT}

The U.S. government and its military currently operate in a wide range of geographic locations. Due to the time, logistics, and costs of shipping or acquiring materials once in theater, it is advantageous for engineers and commanders to understand the relevant environmental conditions present that could cause untimely material degradation, especially for wood and concrete masonry units (CMUs). This publication provides an overview of research conducted to inform a remote selection of operational materials in a wide variety of climates. The information and analytical methods used will be incorporated in development of a remote assessment tool that can predict material degradation based on using global location data, as part of the Engineer Site Identification for the Tactical Environment (ENSITE) program. This document provides background and understanding of the (a) concept of climate zones and their effects on materials selection, (b) environmental factors that drive degradation, (c) mechanisms and other factors that cause degradation of wood and CMUs, and (d) how those mechanisms and factors relate to degradation.

\section{SUBJECT TERMS}

United States--Armed Forces--Military construction operations, Building materials--Deterioration--Climatic factors, Wood--Deterioration--Climatic factors, Concrete masonry--Deterioration--Climatic factors, Military planning

\begin{tabular}{|c|c|c|c|c|c|}
\hline 16. SECURITY C & IFICATION OF: & & 17. LIMITATION & 18. NUMBER & 19a. NAME OF RESPONSIBLE PERSON \\
\hline $\begin{array}{l}\text { a. REPORT } \\
\text { Unclassified }\end{array}$ & $\begin{array}{l}\text { b. ABSTRACT } \\
\text { Unclassified }\end{array}$ & $\begin{array}{l}\text { c. THIS PAGE } \\
\text { Unclassified }\end{array}$ & UU & 42 & $\begin{array}{l}\text { 19b. TELEPHONE NUMBER } \\
\text { (include area code) }\end{array}$ \\
\hline
\end{tabular}

